\title{
Aging induces $B$ cell defects and decreased antibody responses to influenza infection and vaccination
}

\author{
Daniela Frasca ${ }^{*}$ and Bonnie B. Blomberg
}

\begin{abstract}
Background: Aging is characterized by a progressive decline in the capacity of the immune system to fight influenza virus infection and to respond to vaccination. Among the several factors involved, in addition to increased frailty and high-risk conditions, the age-associated decrease in cellular and humoral immune responses plays a relevant role. This is in large part due to inflammaging, the chronic low-grade inflammatory status of the elderly, associated with intrinsic inflammation of the immune cells and decreased immune function.

Results: Aging is usually associated with reduced influenza virus-specific and influenza vaccine-specific antibody responses but some elderly individuals with higher pre-exposure antibody titers, due to a previous infection or vaccination, have less probability to get infected. Examples of this exception are the elderly individuals infected during the 2009 pandemic season who made antibodies with broader epitope recognition and higher avidity than those made by younger individuals. Several studies have allowed the identification of B cell intrinsic defects accounting for sub-optimal antibody responses of elderly individuals. These defects include 1) reduced class switch recombination, responsible for the generation of a secondary response of class switched antibodies, 2) reduced de novo somatic hypermutation of the antibody variable region, 3) reduced binding and neutralization capacity, as well as binding specificity, of the secreted antibodies, 4) increased epigenetic modifications that are associated with lower antibody responses, 5) increased frequencies of inflammatory B cell subsets, and 6) shorter telomeres.

Conclusions: Although influenza vaccination represents the most effective way to prevent influenza infection, vaccines with greater immunogenicity are needed to improve the response of elderly individuals. Recent advances in technology have made possible a broad approach to better understand the age-associated changes in immune cells, needed to design tailored vaccines and effective therapeutic strategies that will be able to improve the immune response of vulnerable individuals.
\end{abstract}

Keywords: Aging, B cells, Antibodies, Influenza infection, Influenza vaccination

\section{Introduction}

Aging is characterized by a progressive and significant decline in immune function, called immunosenescence. Both innate and adaptive, and within the latter, cellular and humoral immune responses are decreased by aging,

\section{* Correspondence: dfrasca@med.miami.edu}

Department of Microbiology and Immunology and Sylvester Comprehensive Cancer Center, University of Miami Miller School of Medicine, RMSB 3146A, 1600 NW 10th Ave, Miami, FL 33136, USA leading to increased frequency and severity of infectious diseases and reduced responses to vaccination $[1,2]$. Hospitalization following infection is more common in the elderly than in younger individuals and is a major contributor to the development of disability [1].

Aging is associated with increased chronic low-grade systemic inflammation, known as inflammaging [3], which represents a significant risk factor for morbidity and mortality of the elderly as it is implicated in the

(c) The Author(s). 2020 Open Access This article is licensed under a Creative Commons Attribution 4.0 International License, which permits use, sharing, adaptation, distribution and reproduction in any medium or format, as long as you give appropriate credit to the original author(s) and the source, provide a link to the Creative Commons licence, and indicate if changes were made. The images or other third party material in this article are included in the article's Creative Commons licence, unless indicated otherwise in a credit line to the material. If material is not included in the article's Creative Commons licence and your intended use is not permitted by statutory regulation or exceeds the permitted use, you will need to obtain permission directly from the copyright holder. To view a copy of this licence, visit http://creativecommons.org/licenses/by/4.0/ The Creative Commons Public Domain Dedication waiver (http://creativecommons.org/publicdomain/zero/1.0/) applies to the data made available in this article, unless otherwise stated in a credit line to the data. 
pathogenesis of several debilitating chronic diseases such as Type-2 Diabetes Mellitus, osteoporosis, Alzheimer's disease, cancer, rheumatoid arthritis, chronic obstructive pulmonary disease, and coronary heart disease, among others. Inflammaging induces intrinsic inflammation in immune cells leading to decreased protective responses against infections and decreased vaccine responses [4-6]. Inflammaging also contributes to metabolic dysfunction and development of insulin resistance (IR) [7].

Inflammaging is driven by several factors, such as single nucleotide polymorphisms in the promoter regions of pro- and anti-inflammatory genes, chronic stimulation of immune cells with pathogens, changes in the composition of the gut microbiota, and cellular senescence [8]. Another mechanism for fueling inflammaging has recently been proposed and called "garbaging". Garbaging indicates the age-related increase in the generation of cell-derived products of damaged or dead cells (endogenous, misplaced or altered molecules). The disposal of these products through the proteasome is significantly decreased by aging, leading to the activation of innate immune cells and consequent release of pro-inflammatory mediators [9].

Decreased $\mathrm{T}$ cell function has been considered for many years the only contributor to immunosenescence. However, age-related defects in other components of the immune system also occur and contribute to the increased frequency and severity of infectious diseases in the elderly. In this review, we primarily focus on human $B$ cell defects with aging, and how these contribute to reduced responses to influenza infection and vaccination. A thorough analysis of $\mathrm{T}$ cell defects contributing to the decreased response to influenza infection and vaccination of the elderly has recently been published [10]. Also, see the articles covering other immune cell defects in this special issue compilation.

\section{Aging is associated with increased rates of influenza infection}

Influenza infection is a global major public health concern. Worldwide, there are millions of hospitalizations and thousands of deaths reported each year due to seasonal epidemics. The establishment of a virologic surveillance network for influenza is challenging for many countries because of the requirements to collect, analyze, and report local viral surveillance data for large numbers of individuals. For this reason, most of the available data have been obtained in high-income countries. Many developing countries have recently improved their influenza surveillance and have developed country-specific influenza-associated mortality estimates, which are generally higher than those calculated by the World Health Organization, suggesting that current global influenza death estimates might underestimate the global mortality burden of influenza. A recent study has calculated countryspecific influenza-associated respiratory excess mortality rates (EMR) in 33 low-income and high-income countries around the world, from 1999 to 2015. The results have shown that EMR ranged from 0.1 to $6.4 / 100,000$ individuals for people younger than 65 years, 2.9 to $44 / 100,000$ individuals for people aged 65-74 years, and 17.9 to $223.5 / 100,000$ for people older than 75 years [11].

The Centers for Disease Control and Prevention monitor laboratory-confirmed influenza infections and associated hospitalizations in the U.S. through the Influenza Hospitalization Surveillance Network (FluSurv-NET) (https://www.cdc.gov/mmwr/volumes/68/wr/mm6824a3. htm). Data from the 2018-2019 season have confirmed previous year data and have shown that hospitalization rates were higher among individuals aged $\geq 65$ years. Almost all (95\%) of the hospitalizations were due to influenza A virus, only $4 \%$ to influenza B virus and $1 \%$ to influenza $\mathrm{A}$ and $\mathrm{B}$ virus co-infection. Among influenza A virus infections, about $50 \%$ were with the $\mathrm{A} / \mathrm{H} 3 \mathrm{~N} 2$, a strain known to lead to heavy seasonal epidemics [12]. $\mathrm{A} / \mathrm{H} 3 \mathrm{~N} 2$ is also the most common virus affecting elderly individuals, leading to the highest hospitalization rates and death [13].

Also, data from Europe collected during the 2018-2019 season (https://www.ecdc.europa.eu/en/publications-data/ seasonal-influenza-annual-epidemiological-report-2018-201 9) have shown the the vast majority of influenza viruses detected were type A, both subtypes (A/H1N1pdm09 and A/ H3N2), with different distributions of A subtypes among different European countries. Very low numbers of type B viruses (B/Yamagata and $\mathrm{B} /$ Victoria) were detected in the 2018-2019 season. ICU cases were mainly aged 65 years and older, with most hospitalizations being due to influenza A infections.

In addition to advanced age and the age-related decrease in immune function, other factors increase the risk of influenza infection. These include chronic diseases, obesity, metabolic diseases, immunosuppression, and neuromuscular disorders [14]. Frailty, a measure of health, physical function and physiologic reserve, also strongly predictive of health outcomes, is another risk factor for influenza infection [15]. Once infected with influenza, elderly individuals are also at increased risk to get other infections with viruses that cause severe respiratory tract (RT) infections, such as respiratory syncytial virus (RSV), parainfluenza virus, rhinovirus, enterovirus, and coronavirus. Influenza infection affects both the upper and the lower respiratory systems, inducing common cold, sinusitis, tonsillitis, pharyngitis and laryngitis in the upper RT, and pneumonia, bronchitis and tuberculosis in the lower RT [16]. The infection with the influenza virus induces several changes that alter the proper function of the RT, as reviewed in [17]. 
Although not specifically demonstrated for infuenza infection, a dysfunctional RT may predispose elderly individuals to be also infected by other pathogens affecting the RT, and there is experimental evidence that in mice infected with influenza alveolar macrophages show sustained desensitization in response to TLR-mediated stimuli, characterized by a significant decrease in chemokine secretion leading to reduced recruitment of neutrophils and heightened bacterial load during secondary RT infections [18].

Since the last months of 2019, Severe Acute Respiratory Syndrome-Coronavirus 2 (SARS-CoV-2) had caused $>26$ million cases of Coronavirus Disease 2019 (COVID-19) and $>870,000$ deaths worldwide (as of September 4th, 2020, https://covid19.who.int). Early reports from China showed that frequency of co-infection with other RT viruses was limited in the whole population $[19,20]$. Nevertheless, the Centers for Disease Control and Prevention endorsed testing for co-infection with other RT viruses, to increase the possibility to detect potential COVID-19 patients (https://www.cdc.gov/coronavirus/2019-ncov/hcp/ clinical-criteria.html). The results from a study conducted by Stanford investigators showed higher rates of coinfection in the whole population, as compared to the initial results from China, with $20.7 \%$ of SARS-CoV-2 positive samples also positive for at least one RT virus. The most common co-infections were with rhinovirus/ enterovirus (6.9\%), RSV (5.2\%) and non-SARS-CoV-2 Coronaviruses $(4.3 \%)$. However, when the analysis was performed in young/adults versus elderly individuals, the frequency of elderly individuals co-infected with SARS-CoV-2 and another RT virus like influenza A virus was only $1 \%$ [21]. At the time that this review is written, there are still conflicting reports as to whether the infection with SARS-CoV-2 increases the rates of co-infection with other RT in the elderly population.

Co-infections with bacteria such as S. pneumoniae have also been reported as a significant cause of morbidity and mortality especially in the elderly and it has been shown that influenza viruses alter the lungs and favor the adherence, invasion and induction of disease by the bacterium. Several published results have clearly demonstrated that influenza virus-induced inflammation, and consequent immune dysfunction, reduce the ability of the host to clear pneumococcus [22]. Interestingly, very recently published observations have shown that the use of seasonal influenza and pneumococcal polysaccharide vaccines reduce COVID-19 mortality in older adults [23].

\section{Aging decreases antibody responses to the influenza virus}

Both cellular and humoral adaptive immune responses play key roles in the clearance of the virus and in protection. The infection is initially controlled by an antibody response which allows time for cytotoxic $\mathrm{T}$ cell-mediated immune responses to develop. Antibodies bind to the hemagglutinin (HA) surface glycoprotein, that allows infection of the host cell, and neutralize the virus. Antibody titers measured by the HemAgglutination Inhibition (HAI) assay remain the gold standard correlate of protection against infection and represent the only measure of vaccine efficacy, although they do not provide clinical protection against influenza-associated complications.

In general, individuals with higher pre-exposure HAI titers have less probability to have a large/productive infection. The 2009 H1N1 pandemic unexpectedly had low morbidity and mortality in older people, likely because older people weve already been exposed to the 1918 pandemic $\mathrm{A} / \mathrm{H} 1 \mathrm{~N} 1$ virus that gave rise to periodic seasonal strains that decreased in frequency only in the late 1950s. The 1918 and the 2009 pandemic A/H1N1 viruses had high levels of similarities, as indicated by the cross-neutralization and protection between the two viruses [24]. In a study conducted in 130 individuals of different ages (0-89 years old), infected with the 2009 H1N1 pandemic strain (H1N1pdm09), an in-depth evaluation of antibody responses was performed [25]. In addition to HAI titers, H1N1pdm09 whole genome fragment phage display libraries were used to evaluate antibody repertoires against internal genes, $\mathrm{HA}$ and neuraminidase, and to measure antibody affinity for antigenic domains within HA. Results showed that the infection of elderly individuals ( $\geq 70$ years old) induced antibodies with broader epitope recognition than those induced in younger individuals $(0$ 69 years old). Importantly, serum antibodies of elderly individuals had significantly higher avidity for the HA1 globular domain, but not for the conserved HA2 stalk, than those from younger individuals and lower antibody dissociation rates measured by surface plasmon resonance. This study provided the first evidence for a qualitatively superior antibody response in the elderly following H1N1pdm09 infection, suggestive of recall of long-term memory B cells or long-lived plasma cells [25].

\section{Aging decreases influenza vaccine-specific antibody responses}

Despite reduced efficacy in elderly individuals, influenza vaccination is still the most effective way to prevent influenza infection and represents a cost-effective strategy, although it is clear that vaccines with greater immunogenicity are needed to improve the response of the elderly [26]. Vaccination has been shown to significantly reduce disease burden and influenza transmission within the community. Several vaccines are approved in the United States for seasonal influenza vaccination each year. Influenza vaccines require annual reformulation due to continuous viral evolution (antigenic drift and 
shift) which allows new human and non-human influenza viruses to infect human individuals. Annual influenza vaccination campaigns help individuals to make protective antibodies specific for the currently circulating strains. Influenza vaccines induce an antiviral response in $\mathrm{B}$ and $\mathrm{T}$ cells, and humoral and cellular immunity, respectively [27]. The antibody response to the vaccine represents the first line of protection from subsequent infection, with IgM antibodies providing initial protection, whereas class switched antibodies (IgA and IgG) neutralize newly replicating virus once infection has been established [28]. Although for a long time it has been believed that there is no pre-existing immunity to newly emerging influenza variants in humans $[29,30]$, it has been demonstrated that seasonal influenza vaccination can induce polyclonal heterosubtypic neutralizing antibodies which are crossreactive with both the swine-origin $\mathrm{H} 1 \mathrm{~N} 1 \mathrm{pdm} 09$ virus and the H5N1 avian virus [31].

Both the production and the duration of vaccinespecific high affinity protective antibodies decrease with age [32] and therefore yearly vaccination with the current influenza vaccine is strongly recommended for individuals $\geq 65$ years of age to protect them from infection and associated complications. Young individuals respond better than elderly individuals to the first influenza vaccination. However, after repeated vaccinations with the same vaccine that increase vaccine-specific serum antibody titers [33], the difference between young and elderly individuals decreases, suggesting the importance of the history of an individual that includes previous vaccination and/or infection [34]. Influenza vaccine-specific antibodies do not persist year-round in older adults, and therefore alternative vaccination strategies providing better clinical benefits are needed [35]. It has indeed been shown that elderly individuals who have received the influenza vaccine can still be infected and can also get severe secondary complications such as hospitalization, catastrophic disability, exacerbation of underlying medical conditions and death [36-38], likely due to a compromised immune system in these individuals. Although vaccination rates have increased over the years, with $>60 \%$ vaccination rates in individuals $\geq 65$ years of age in many countries, influenza is still a serious threat for the elderly, and it has been shown that in the U.S. $\geq 65$ year old individuals account for $2 / 3$ of the 200 , 000 influenza-related hospitalizations, independently of associated conditions. Moreover, the length of hospital stay for elderly individuals is almost 3- and 6-fold higher than middle age (50-64 year old) and younger individuals, respectively [10].

In addition to age, several causes determine the limited success of influenza vaccination among elderly adults. These include preexisting immunity, genetic polymorphisms, and the presence of chronic underlying conditions may compromise the influenza vaccine response
[39, 40]. These factors are also relevant in younger individuals.

Systems vaccinology approaches have recently been successfully employed to evaluate and characterize innate and adaptive immune responses to the influenza vaccine. Systems vaccinology, employing systems biology approaches to identify molecular signatures at early post-vaccination time points (1-3 days), has provided a global picture of the immune response to the influenza vaccine. In a study conducted on 212 individuals of different ages recruited across 5 consecutive influenza vaccine seasons (2007-2011), we found, as expected, that the antibody response to the vaccine was negatively associated with age (not with gender and race) [41]. We performed a gene set enrichment analysis of genes correlated with the HAI response in each season and we found that signatures of innate immunity and plasmablasts were not only associated with, but also predicted, post-vaccination antibody titers with $>80 \%$ accuracy across multiple seasons. However, these signatures were not associated with the duration of the response. We also found that early post-vaccination signatures of inflammatory pathways in lymphocytes were positively associated (whereas those in monocytes were negatively associated) with post-vaccination antibody titers. The importance of these results relies in the identification of shared signatures of influenza vaccine-specific antibody responses across multiple seasons that can help to develop next-generation vaccines that can be highly protective.

Many other systems vaccinology studies have evaluated gene expression and cellular signatures correlated with protective responses to the influenza vaccine. Among these, a multicenter analysis has identified baseline transcriptional signatures that are significantly associated with vaccine-specific antibody responses in different cohorts recruited through the Human Immunology Project Consortium and the Center for Human Immunology, and applied a common quantitative metric to stratify relative vaccine responses in all cohorts. These validated signatures were specific to young vaccinees $(<35$ years of age) but their effect sizes (strength of correlation with antibody responses) were also correlated in older participants. Some of these signatures have already been found in earlier studies and were primarily related to the frequencies of peripheral immune cell subsets, whereas others revealed the involvement of previously unreported genes and pathways, such as autophagy, anti-viral innate immunity, antigen presentation, BCR signaling [42]. In another study, baseline transcripts found significantly correlated with antibody responses were enriched for pattern recognition and interferon signaling [43], for age- and apoptosis-related gene module [44] or for lipid biosynthesis, also associated with sex and testosterone-dependent differences in the 
antibody response [45]. When the expression of markers of immunosenescence (age, frequency of $\mathrm{T}$ cell receptor excision circle, telomerase expression, frequencies of CD4+ CD28- and CD8+ CD28- T cells, CD4/CD8 T cell ratios) was evaluated, it was found that immunosenescence-related differences in gene expression, gene regulation, cytokine secretion, and immunologic changes were able to predict the lower response of older adults to seasonal influenza A/ H1N1 vaccination [46]. Sex differential responses to the vaccine were also identified [47]. Gene expression patterns associated with vaccine-specific antibody responses were found to be different between young and old vaccinees also in another study in which the post-vaccination increase in the expression of KLRB1 (killer cell lectin-like receptor B1) was positively associated with vaccine-specific antibody responses in young but not in older adults [48]. A metaanalysis combined publicly available influenza microarray data with the aim of identifying the effects of disease (influenza infection, influenza vaccination, controls), age and sex on gene expression. Results have identified around 1000 differentially expressed genes when results were filtered by disease factor, and gene enrichment analysis, with statistically significant disease-age interactions. Genes included innate immune response, viral process, defense response to virus, hematopoietic cell lineage and NF-kB signaling pathway [49]. A mitochondrial signature of young and old influenza vaccine responders has identified genes and proteins controlling mitochondrial biogenesis and pathways of oxidative phosphorylation [50]. It was found that these pathways and genes involved in cellular respiration, heme biosynthesis, mitochondrial DNA transcription and regulation were up-regulated in young and, to a significantly lower extent, in older vaccine responders. This study was the first genome-wide transcriptional analysis of age-associated metabolic measures performed before and after influenza vaccination, showing the crucial role of mitochondrial pathways in influenza vaccine responses.

\section{Mechanisms for reduced influenza vaccine-specific antibody responses in the elderly}

Age-related changes in the function of T cells [32, 51-53], NK cells $[54,55]$ and antigen-presenting cells $[56,57]$ have been shown to contribute to the reduced influenza vaccine-specific response in the elderly and increased frequency and severity of influenza infection. We have previously identified intrinsic $B$ cell defects with age also accounting for the sub-optimal influenza vaccine response of elderly individuals [5, 58-63]. We will summarize below published results on age-related changes in B cells, focusing on the cellular and molecular mechanisms involved in the regulation of influenza vaccine responses.

\section{Age effects on class switch recombination (CSR) and somatic hypermutation (SHM)}

The B cell intrinsic age-related defects in class switch recombination (CSR) and somatic hypermutation (SHM) lead to sub-optimal antibody responses to the influenza vaccine. CSR and SHM are two processes needed for the generation of secondary class switched high affinity antibodies [64]. Reduced CSR and SHM with age in mice and humans are due to decreased expression of activationinduced cytidine deaminase (AID) and of E47 [65], encoded by the E2A gene, a key transcription factor regulating AID [66]. Also PAX5, another key regulator of CSR and antibody production $[67,68]$, has recently been shown to be reduced in mature B cells from elderly as compared to young individuals and to be associated with the expansion of pro-inflammatory B cell subsets [69], which are unable to respond to influenza vaccination [70].

We have measured the $\mathrm{B}$ cell antibody response to the influenza vaccine in vivo and in vitro, by HAI and by AID mRNA expression by qPCR after in vitro restimulation with the vaccine, respectively. Both responses are decreased with age and are significantly correlated, supporting our initial hypothesis that the in vitro AID response recapitulates what has occurred in vivo in the germinal center in the generation of memory B cells. After 2009, the H1N1pdm09 has been repeated in the vaccine preparation for several years, leading to higher levels of seroprotection in vaccinated individuals, suggesting that the memory B cells to $\mathrm{H} 1 \mathrm{~N} 1$ can be stimulated in elderly individuals [71, 72].

We have evaluated if AID was also involved in antibody affinity maturation in young and elderly individuals vaccinated with the H1N1pdm09 vaccine. We found that in both young and elderly individuals the fold-increase in AID after vaccination correlated with fold-increase in polyclonal antibody affinity to the globular HA1 (but not to the conserved HA2) antigen of the H1N1pdm09. Affinity maturation to the HA1 domain was observed after vaccination only in young individuals. In the elderly, high affinity antibodies specific for the HA1 domain were already present before vaccination and the change in antibody affinity was almost undiscernible, suggesting a previous vaccination or infection with highly conserved H1N1pdm09 determinants which were able to generate an optimal memory response. These findings were the first to demonstrate a strong correlation between AID induction and in vivo antibody affinity maturation in humans [72].

\section{Age effects on the generation of memory $B$ cells}

Despite the age-related decrease in AID, influenza vaccine-specific memory $B$ cells are maintained in the elderly after repeated vaccination with a vaccine containing the same H1N1pdm09, but the fold-increase in HAI 
titers after vaccination is lower in the elderly although most of them are seroprotected, suggesting that low seroconversion in the elderly may be mainly due to cell intrinsic defects in the differentiation of B memory cells to plasmablasts/antibody-secreting cells (ASCs) [71]. The analysis of the antibodies secreted from single plasmablasts 7 days after influenza vaccination has indeed shown an age-related decrease not only in the number of vaccine-specific plasmablasts, but also in the quantity of antibodies made by these cells [73]. One possible explanation for similar memory B cell responses in young and elderly individuals is that B cells carrying a switched IgG receptor could be positively selected, and proliferate in response to repeated vaccinations, in elderly individuals similar to what has been observed in aged mice [74]. Influenza vaccine-specific memory B cells represent an important pool of cells able to mount a rapid secondary immune response and contribute to both short-term and long-term immunity. These data altogether suggest that at least in the case of influenza vaccine, due to intrinsic age-related impairment in the differentiation of ASCs, regular booster vaccinations are highly recommended to induce seroprotective titers and protect the elderly from influenza infection.

\section{Age effects on B cell repertoire}

Although there is an age-related decrease in the number of vaccine-specific plasmablasts, as well as in the quantity of antibodies made by these cells, the avidity of vaccine-specific antibodies and the affinity of recombinant monoclonal antibodies obtained from single plasmablasts seem to be not significantly different in young and elderly individuals [73]. In agreement with these findings, the analysis of the clonal structure and mutation distribution of B cell repertoires has shown that elderly individuals had decreased numbers of lineages but increased pre-vaccination mutation load in their repertoire, suggesting previous infections or vaccinations [75]. Moreover, some of these individuals have an oligoclonal repertoire in which the diversity of the lineages is greatly reduced as compared to young individuals, consistent with earlier reports on contraction of B cell repertoires in the elderly [76]. The spectratype analysis and highthroughput sequencing, the B cell repertoire of elderly individuals has shown evidence of non-specific clonal expansions in the absence of challenge, with this loss of specific B cell diversity being correlated with poor health [77]. Another study, also showing comparable blood frequencies of plasmablasts in young and elderly individuals, showed similar V/D/J usage in young and elderly vaccine responders. However, recombinant antibodies generated from plasmablasts of elderly vaccine responders bound a broader number of HA epitopes, indicating an increased breadth of binding across influenza strains [78].

High-throughput DNA sequencing of B cell receptor IgH gene rearrangements occurring in vaccinated young and elderly individuals has shown that $\mathrm{V} / \mathrm{D} / \mathrm{J}$ usage is similar in B cells from young and elderly individuals. Moreover, because seropositivity with latent viruses such as cytomegalovirus (CMV) or Epstein-Barr virus (EBV) may change the $B$ cell repertoire, CMV-positive and EBV-positive individuals of different ages were evaluated. It was found that infection with both CMV and EBV alters the B cell repertoire, regardless of the individual's age, with CMV infection being correlated with the proportion of $\mathrm{V}_{\mathrm{H}}$ mutations in IgM and IgG antibodies and EBV infection being correlated with the presence of persistent clonal B cell expansions [79].

An age-related decrease in the accumulation of de novo mutations in antibodies induced by influenza vaccination was reported and found to be associated with reduced binding capacity of the antibodies to the viral glycoprotein HA and reduced neutralization capacity. These antibodies were also targeting non-HA epitopes [80]. Antibodies with de novo mutations are those able to adapt to drifted and shifted influenza viruses and are therefore highly protective. It has been shown that antibodies from elderly individuals predominantly target highly conserved (but not potent) epitopes outside the HA receptor-binding site, and generate less protection [80]. These results have suggested that elderly individuals rely on cross-reactive memory B cells generated early in life for protection.

\section{Effects of age-associated epigenetic modifications on influenza vaccine responses}

A recent study of baseline whole genome DNA methylation in peripheral blood mononuclear cells of responders and non-responders to the influenza vaccine of different ages has identified possible age-related DNA methylation contributors to vaccine responsiveness [81]. This study discovered 142 differentially methylated CpG sites in young and 305 in elderly individuals, respectively, suggesting a larger epigenetic remodeling with aging. Interestingly, some of the differentially methylated probes mapped in genes involved in immunosenescence (CD40) [82] and in innate immune responses during viral infections (CXCL16, ULK1, BCL11B) [83-85]. Another study on epigenetic and transcriptomic profiles and humoral immune responses in young and elderly recipients of the influenza vaccine has also shown associations between DNA methylation and gene expression and has revealed a system-wide regulation of immune relevant functions that play crucial roles in regulating the participant's capacity to respond to vaccination. Results have identified a group of CpGs that are associated with lower or higher 
antibody responses, when coordinately hypo-methylated or hyper-methylated, respectively. Interestingly, CpGs that individually predict antibody responses are enriched for FOXP2 transcription factor binding sites, with the most robust associations involving differential methylation of genes associated with immunity and immunosenescence [86]. These studies, leading to the identification of differentially methylated CpG sites between responders and non-responders to the influenza vaccine, represent an important step to gain knowledge on potential targets of immunosenescence that may help to design better vaccines for the elderly.

\section{Age effects on B cell subsets}

Another mechanism that can account for the reduced B cell response to the influenza vaccine in the elderly is the well-defined redistribution of peripheral B cell subsets that occurs during aging, with a significant expansion of a subset of B cells that is the most pro-inflammatory, called Double Negative (DN) B cells, as we [87, 88] and others $[89,90]$ have reported. These cells, also called late/ exhausted memory or tissue-like memory B cells, have been identified as CD19+CD27-IgD- and have been shown to be increased in the blood of patients with autoimmune [89, 91, 92] and infectious diseases [93-95], and it has been suggested that they may expand in vivo in the presence of autoantigens or pathogen-derived antigens, in the context of a favorable inflammatory microenvironment, leading to the production of autoimmune or protective antibodies, respectively. Their frequencies in blood are negatively associated with the serum response to the influenza vaccine [87], due to the fact that they secrete large amounts of pro-inflammatory cytokines making them refractory to further stimulation. DN B cells do not proliferate and do not make antibodies to influenza antigens, but they secrete antibodies with autoimmune reactivity, in agreement with their membrane phenotype $(\mathrm{CD} 95+\mathrm{CD} 21-\mathrm{CD} 11 \mathrm{c}+)$ and their spontaneous expression of the transcription factor T-bet, both characteristics of autoimmune B cells [70].

DN B cells are the human equivalent of the subset of mouse splenic B cells called Age-associated B Cells (ABC) $[96,97]$. Both DN B cells and ABCs are generated from conventional mature $B$ cell subsets (naïve in humans, follicular B cells in mice) after in vivo or in vitro stimulation with the endosomal nucleic acidsensing Toll-like receptors TLR7 or TLR9, alone or together with $\mathrm{BCR}$ cross-linking, demonstrating that $\mathrm{BCR}$ is also an active signaling system in these subsets. TLR engagement in the presence of the cytokines IL-21 and IFN- $\gamma$ regulate T-bet expression, whereas in the presence of IL-21 alone promotes CD11c expression independently of T-bet [98]. T-bet+ ABCs carry high frequencies of somatically mutated Ig, suggesting that they originate during T-dependent B cell responses [99]. T-bet+ ABCs appear and persist indefinitely after influenza infection in mice $[98,99]$. These cells represent the spleen-resident population of memory B cells esponsible for the secretion of HA stalk-specific IgG2c antibodies and of durable neutralizing antibodies [100]. Previous results from a different group have also demonstrated the specificity of mouse $A B C s$ for a live influenza virus (A/ $\mathrm{PR} 8 / 34)$ and these influenza-specific $\mathrm{ABCs}$ differentiate into antibody-secreting cells, some of which home to the bone marrow and to the lungs, and persist for long periods of time after infection ( $>4$ weeks), suggesting their role in providing significant protection [101]. Human Tbet+ $B$ cells also have been shown to mediate influenzaspecific humoral memory [100]. Similar to mouse Tbet+ $\mathrm{ABCs}$, they have an activated phenotype, they are spleen-resident and secrete HA-specific IgG1 (the equivalent of mouse IgG2c) antibodies recognizing $\mathrm{H} 1$ or $\mathrm{H} 3$ viral strains.

DN B cells increase under obesity conditions, reaching significantly high frequencies (up to $50 \%$ of total B cells) in the obese subcutaneous adipose tissue (AT), where they also secrete large amounts of autoimmune antibodies specific for adipocyte-derived proteins, supporting the hypothesis that DN B cells would generate suboptimal immune responses by circulating to peripheral lymphoid organs. The AT is the largest organ in humans and therefore age-related changes in AT composition and function, as well as in AT metabolism, may lead to significant systemic changes which in turn may accelerate and exacerbate the aging process. Fat mass increases with age in humans $[102,103]$ and this is associated with increased inflammaging [3], which contributes to metabolic dysfunction and development of IR which also increases with age. Moreover, an age-associated increase in the ectopic deposit of triglycerides in several tissues (liver, muscle, heart, pancreas, kidney) [104-108] and in blood vessels [109] occurs, and this is associated with the development and/or progression of age-associated diseases.

\section{Age effects on telomeres}

B cells from elderly individuals with protective titers to the influenza vaccine had significantly longer telomeres than those with poor antibody responses [110], suggesting a role of telomeres in supporting the expansion of vaccine-specific $B$ cells by preserving their replicative lifespan. Telomeres are specialized terminal chromosomal structures that consist of tandem hexanucleotide repeats (TTAGGG)n and telomere binding proteins with the function of maintaining the integrity of chromosomes during chromosomal replication [111]. Based on these results, it is likely that the age-related decrease in telomeres can be another mechanism explaining why $\mathrm{B}$ 
cells from some elderly individuals cannot proliferate and differentiate in response to the influenza vaccine.

\section{Conclusions}

Aging decreases antibody responses to the influenza virus and to the influenza vaccine. The decreased antibody response to the influenza virus is best exemplified by the decreased influenza vaccine efficacy, and several studies have identified the molecular mechanisms responsible for sub-optimal antibody responses of elderly individuals. Although influenza vaccination represents the most effective way to prevent influenza infection, vaccines with greater immunogenicity are still needed now to overcome the immune defects and improve the response of elderly individuals. Systems vaccinology approaches have better characterized the age-associated immune defects which can be used to design tailored vaccines and better therapeutic strategies to induce stronger humoral and cell-mediated immunity in vulnerable individuals like the elderly.

\section{Abbreviations}

AID: Activation-induced cytidine deaminase; ASCs: Antibody-secreting cells; CMV: Cytomegalovirus; CSR: Class switch recombination; EMR: Excess mortality rates; HA: Hemagglutinin; HAl: Hemagglutination inhibition; RT: Respiratory tract; SHM: Somatic hypermutation

\section{Authors' contributions}

DF wrote the review. DF and BBB were involved in funding acquisition, reviewing and editing the manuscript. The authors read and approved the final manuscript.

\section{Funding}

Study supported by NIH awards AG32576, AG059719, and AG023717.

\section{Availability of data and materials}

Not applicable.

\section{Ethics approval and consent to participate}

Not applicable.

\section{Consent for publication}

Not applicable.

\section{Competing interests}

The authors declare that they have no competing interests.

Received: 1 July 2020 Accepted: 16 November 2020

Published online: 19 November 2020

\section{References}

1. Ferrucci L, Guralnik JM, Pahor M, Corti MC, Havlik RJ. Hospital diagnoses, Medicare charges, and nursing home admissions in the year when older persons become severely disabled. JAMA. 1997;277(9):728-34.

2. McElhaney JE, Effros RB. Immunosenescence: what does it mean to health outcomes in older adults? Curr Opin Immunol. 2009;21(4):418-24

3. Franceschi C, Bonafe M, Valensin S, Olivieri F, De Luca M, Ottaviani E, De Benedictis $G$. Inflamm-aging. An evolutionary perspective on immunosenescence. Ann N Y Acad Sci. 2000:908:244-54.

4. Bryl E, Vallejo AN, Weyand CM, Goronzy JJ. Down-regulation of CD28 expression by TNF-alpha. J Immunol. 2001;167(6):3231-8.

5. Frasca D, Diaz A, Romero M, Landin AM, Blomberg BB. High TNF-alpha levels in resting $B$ cells negatively correlate with their response. Exp Gerontol. 2014;54:116-22.
6. Parish ST, Wu JE, Effros RB. Modulation of T lymphocyte replicative senescence via TNF-\{alpha\} inhibition: role of caspase-3. J Immunol. 2009; 182(7):4237-43.

7. Hotamisligil GS. Inflammation, metaflammation and immunometabolic disorders. Nature. 2017;542(7640):177-85.

8. Frasca D, Blomberg BB. Inflammaging decreases adaptive and innate immune responses in mice and humans. Biogerontology. 2016;17(1):7-19.

9. Franceschi C, Garagnani P, Vitale G, Capri M, Salvioli S. Inflammaging and 'Garb-aging'. Trends Endocrinol Metab. 2017;28(3):199-212.

10. McElhaney JE, Verschoor CP, Andrew MK, Haynes L, Kuchel GA, Pawelec G. The immune response to influenza in older humans: beyond immune senescence. Immun Ageing. 2020;17:10

11. Iuliano AD, Roguski KM, Chang HH, Muscatello DJ, Palekar R, Tempia S, Cohen C, Gran JM, Schanzer D, Cowling BJ, et al. Estimates of global seasonal influenza-associated respiratory mortality: a modelling study. Lancet. 2018;391(10127):1285-300.

12. Allen JD, Ross TM. H3N2 influenza viruses in humans: viral mechanisms, evolution, and evaluation. Hum Vaccin Immunother. 2018;14(8):1840-7.

13. Thompson WW, Shay DK, Weintraub E, Brammer L, Cox N, Anderson LJ, Fukuda K. Mortality associated with influenza and respiratory syncytial virus in the United States. JAMA. 2003;289(2):179-86.

14. Louie JK, Acosta M, Winter K, Jean C, Gavali S, Schechter R, Vugia D, Harriman K, Matyas B, Glaser CA, et al. Factors associated with death or hospitalization due to pandemic 2009 influenza $A(H 1 N 1)$ infection in California. JAMA. 2009;302(17):1896-902.

15. Clegg A, Young J, lliffe S, Rikkert MO, Rockwood K. Frailty in elderly people. Lancet. 2013;381(9868):752-62

16. Haq K, McElhaney JE. Ageing and respiratory infections: the airway of ageing. Immunol Lett. 2014;162(1 Pt B):323-8.

17. Herold S, Becker C, Ridge KM, Budinger GR. Influenza virus-induced lung injury: pathogenesis and implications for treatment. Eur Respir J. 2015;45(5): $1463-78$

18. Didierlaurent A, Goulding J, Patel S, Snelgrove R, Low L, Bebien M, Lawrence T, van Rijt LS, Lambrecht BN, Sirard JC, et al. Sustained desensitization to bacterial toll-like receptor ligands after resolution of respiratory influenza infection. J Exp Med. 2008;205(2):323-9.

19. Chen N, Zhou M, Dong X, Qu J, Gong F, Han Y, Qiu Y, Wang J, Liu Y, Wei Y, et al. Epidemiological and clinical characteristics of 99 cases of 2019 novel coronavirus pneumonia in Wuhan, China: a descriptive study. Lancet. 2020; 395(10223):507-13.

20. Ding Q, Lu P, Fan Y, Xia Y, Liu M. The clinical characteristics of pneumonia patients coinfected with 2019 novel coronavirus and influenza virus in Wuhan, China. J Med Virol. 2020

21. Kim D, Quinn J, Pinsky B, Shah NH, Brown I. Rates of co-infection between SARS-CoV-2 and other respiratory pathogens. JAMA. 2020.

22. McCullers JA. Insights into the interaction between influenza virus and pneumococcus. Clin Microbiol Rev. 2006:19(3):571-82.

23. Thindwa D, Garcia Quesada M, Liu Y, Bennett J, Cohen C, Knoll MD, von Gottberg A, Hayford K, Flasche S. Use of seasonal influenza and pneumococcal polysaccharide vaccines in older adults to reduce COVID-19 mortality. Vaccine. 2020;38(34):5398-401.

24. Wei CJ, Boyington JC, Dai K, Houser KV, Pearce MB, Kong WP, Yang ZY, Tumpey TM, Nabel GJ. Cross-neutralization of 1918 and 2009 influenza viruses: role of glycans in viral evolution and vaccine design. Sci Transl Med. 2010:2(24):24ra21

25. Verma N, Dimitrova M, Carter DM, Crevar CJ, Ross TM, Golding H, Khurana S Influenza virus H1N1pdm09 infections in the young and old: evidence of greater antibody diversity and affinity for the hemagglutinin globular head domain (HA1 domain) in the elderly than in young adults and children. J Virol. 2012:86(10):5515-22

26. Finco O, Rappuoli R. Designing vaccines for the twenty-first century society. Front Immunol. 2014:5:12

27. Murasko DM, Bernstein ED, Gardner EM, Gross P, Munk G, Dran S, Abrutyn E. Role of humoral and cell-mediated immunity in protection from influenza disease after immunization of healthy elderly. Exp Gerontol. 2002;37(2-3): 427-39.

28. Burlington DB, Clements ML, Meiklejohn G, Phelan M, Murphy BR. Hemagglutinin-specific antibody responses in immunoglobulin $\mathrm{G}$, a, and $\mathrm{M}$ isotypes as measured by enzyme-linked immunosorbent assay after primary or secondary infection of humans with influenza A virus. Infect Immun. 1983:41(2):540-5. 
29. McMurry JA, Johansson BE, De Groot AS. A call to cellular \& humoral arms: enlisting cognate $T$ cell help to develop broad-spectrum vaccines against influenza A. Hum Vaccin. 2008;4(2):148-57.

30. Wrammert J, Smith K, Miller J, Langley WA, Kokko K, Larsen C, Zheng NY, Mays I, Garman L, Helms C, et al. Rapid cloning of high-affinity human monoclonal antibodies against influenza virus. Nature. 2008;453(7195):667-71.

31. Corti D, Suguitan AL Jr, Pinna D, Silacci C, Fernandez-Rodriguez BM, Vanzetta F, Santos C, Luke CJ, Torres-Velez FJ, Temperton NJ, et al. Heterosubtypic neutralizing antibodies are produced by individuals immunized with a seasonal influenza vaccine. J Clin Invest. 2010;120(5):1663-73.

32. Saurwein-Teissl M, Lung TL, Marx F, Gschosser C, Asch E, Blasko I, Parson W, Bock G, Schonitzer D, Trannoy E, et al. Lack of antibody production following immunization in old age: association with CD8(+)CD28(-) T cell clonal expansions and an imbalance in the production of Th1 and Th2 cytokines. J Immunol. 2002;168(11):5893-9.

33. Andrews SF, Kaur K, Pauli NT, Huang M, Huang Y, Wilson PC. High preexisting serological antibody levels correlate with diversification of the influenza vaccine response. J Virol. 2015;89(6):3308-17.

34. Mosterin Hopping A, McElhaney J, Fonville JM, Powers DC, Beyer WEP, Smith DJ. The confounded effects of age and exposure history in response to influenza vaccination. Vaccine. 2016;34(4):540-6.

35. Young B, Zhao X, Cook AR, Parry CM, Wilder-Smith A, MCIC. Do antibody responses to the influenza vaccine persist year-round in the elderly? $\mathrm{A}$ systematic review and meta-analysis. Vaccine. 2017;35(2):212-21.

36. Gross PA, Hermogenes AW, Sacks HS, Lau J, Levandowski RA. The efficacy of influenza vaccine in elderly persons. A meta-analysis and review of the literature. Ann Intern Med. 1995;123(7):518-27.

37. Simonsen L, Taylor RJ, Viboud C, Miller MA, Jackson LA. Mortality benefits of influenza vaccination in elderly people: an ongoing controversy. Lancet Infect Dis. 2007:7(10):658-66.

38. Vu T, Farish S, Jenkins M, Kelly H. A meta-analysis of effectiveness of influenza vaccine in persons aged 65 years and over living in the community. Vaccine. 2002;20(13-14):1831-6.

39. Castrucci MR. Factors affecting immune responses to the influenza vaccine. Hum Vaccin Immunother. 2018;14(3):637-46.

40. Dhakal S, Klein SL. Host Factors Impact Vaccine Efficacy: Implications for Seasonal and Universal Influenza Vaccine Programs. J Virol. 2019;93(21): e00797-19. https://doi.org/10.1128/JVl.00797-19.

41. Nakaya HI, Hagan T, Duraisingham SS, Lee EK, Kwissa M, Rouphael N, Frasca D, Gersten M, Mehta AK, Gaujoux R, et al. Systems analysis of immunity to influenza vaccination across multiple years and in diverse populations reveals shared molecular signatures. Immunity. 2015;43(6):1186-98.

42. Team H-CSP, Consortium H-I. Multicohort analysis reveals baseline transcriptional predictors of influenza vaccination responses. Sci Immunol. 2017;2(14):eaal4656.

43. Tsang JS, Schwartzberg PL, Kotliarov Y, Biancotto A, Xie Z, Germain RN, Wang E, Olnes MJ, Narayanan M, Golding H, et al. Global analyses of human immune variation reveal baseline predictors of postvaccination responses. Cell. 2014;157(2):499-513.

44. Furman D, Jojic V, Kidd B, Shen-Orr S, Price J, Jarrell J, Tse T, Huang H, Lund $\mathrm{P}$, Maecker HT, et al. Apoptosis and other immune biomarkers predict influenza vaccine responsiveness. Mol Syst Biol. 2013;9:659.

45. Furman D, Hejblum BP, Simon N, Jojic V, Dekker CL, Thiebaut R, Tibshirani RJ, Davis MM. Systems analysis of sex differences reveals an immunosuppressive role for testosterone in the response to influenza vaccination. Proc Natl Acad Sci U S A. 2014;111(2):869-74.

46. Kennedy RB, Ovsyannikova IG, Haralambieva IH, Oberg AL, Zimmermann MT, Grill DE, Poland GA. Immunosenescence-related Transcriptomic and immunologic changes in older individuals following influenza vaccination. Front Immunol. 2016;7:450.

47. Voigt EA, Ovsyannikova IG, Kennedy RB, Grill DE, Goergen KM, Schaid DJ, Poland GA. Sex differences in older Adults' immune responses to seasonal influenza vaccination. Front Immunol. 2019;10:180

48. Avey S, Mohanty S, Chawla DG, Meng H, Bandaranayake T, Ueda I, Zapata HJ, Park K, Blevins TP, Tsang S, et al. Seasonal variability and shared molecular signatures of inactivated influenza vaccination in Young and older adults. J Immunol. 2020;204(6):1661-73.

49. Rogers LRK, de Los CG, Mias Gl. Microarray gene expression dataset reanalysis reveals variability in influenza infection and vaccination. Front Immunol. 2019:10:2616.
50. Thakar J, Mohanty S, West AP, Joshi SR, Ueda I, Wilson J, Meng H, Blevins TP, Tsang $\mathrm{S}$, Trentalange $\mathrm{M}$, et al. Aging-dependent alterations in gene expression and a mitochondrial signature of responsiveness to human influenza vaccination. Aging (Albany NY). 2015;7(1):38-52

51. Derhovanessian E, Theeten H, Hahnel K, Van Damme P, Cools N, Pawelec G. Cytomegalovirus-associated accumulation of late-differentiated CD4 T-cells correlates with poor humoral response to influenza vaccination. Vaccine. 2013;31(4):685-90.

52. McElhaney JE, Ewen C, Zhou X, Kane KP, Xie D, Hager WD, Barry MB, Kleppinger A, Wang Y, Bleackley RC. Granzyme B: correlates with protection and enhanced CTL response to influenza vaccination in older adults. Vaccine. 2009;27(18):2418-25

53. McElhaney JE, Zhou X, Talbot HK, Soethout E, Bleackley RC, Granville DJ, Pawelec G. The unmet need in the elderly: how immunosenescence, CMV infection, co-morbidities and frailty are a challenge for the development of more effective influenza vaccines. Vaccine. 2012;30(12):2060-7.

54. Beli E, Clinthorne JF, Duriancik DM, Hwang I, Kim S, Gardner EM. Natural killer cell function is altered during the primary response of aged mice to influenza infection. Mech Ageing Dev. 2011;132(10):503-10.

55. Przemska-Kosicka A, Childs CE, Maidens C, Dong H, Todd S, Gosney MA, Tuohy KM, Yaqoob P. Age-related changes in the natural killer cell response to seasonal influenza vaccination are not influenced by a Synbiotic: a randomised controlled trial. Front Immunol. 2018;9:591.

56. Mohanty S, Joshi SR, Ueda I, Wilson J, Blevins TP, Siconolfi B, Meng H, Devine L, Raddassi K, Tsang S, et al. Prolonged proinflammatory cytokine production in monocytes modulated by interleukin 10 after influenza vaccination in older adults. J Infect Dis. 2015;211(7):1174-84.

57. Panda A, Qian F, Mohanty S, van Duin D, Newman FK, Zhang L, Chen S, Towle $V$, Belshe RB, Fikrig E, et al. Age-associated decrease in TLR function in primary human dendritic cells predicts influenza vaccine response. J Immunol. 2010;184(5):2518-27.

58. Frasca D, Diaz A, Romero M, Ferracci F, Blomberg BB. MicroRNAs miR-155 and miR-16 decrease AID and E47 in B cells from elderly individuals. J Immunol. 2015:195(5):2134-40.

59. Frasca D, Diaz A, Romero M, Landin AM, Phillips M, Lechner SC, Ryan JG, Blomberg BB. Intrinsic defects in B cell response to seasonal influenza vaccination in elderly humans. Vaccine. 2010;28(51):8077-84.

60. Frasca D, Diaz A, Romero M, Mendez NV, Landin AM, Blomberg BB. Effects of age on H1N1-specific serum lgG1 and lgG3 levels evaluated during the 2011-2012 influenza vaccine season. Immun Ageing. 2013;10(1):14.

61. Frasca D, Diaz A, Romero M, Mendez NV, Landin AM, Ryan JG, Blomberg BB. Young and elderly patients with type 2 diabetes have optimal B cell responses to the seasonal influenza vaccine. Vaccine. 2013;31(35):3603-10.

62. Frasca D, Diaz A, Romero M, Phillips M, Mendez NV, Landin AM, Blomberg BB. Unique biomarkers for B-cell function predict the serum response to pandemic H1N1 influenza vaccine. Int Immunol. 2012.

63. Frasca D, Ferracci F, Diaz A, Romero M, Lechner S, Blomberg BB. Obesity decreases $B$ cell responses in young and elderly individuals. Obesity (Silver Spring). 2016;24(3):615-25.

64. Muramatsu M, Kinoshita K, Fagarasan S, Yamada S, Shinkai Y, Honjo T. Class switch recombination and hypermutation require activation-induced cytidine deaminase (AID), a potential RNA editing enzyme. Cell. 2000;102(5): 553-63.

65. Frasca D, Landin AM, Lechner SC, Ryan JG, Schwartz R, Riley RL, Blomberg $B B$. Aging down-regulates the transcription factor E2A, activation-induced cytidine deaminase, and Ig class switch in human B cells. J Immunol. 2008; 180(8):5283-90.

66. Sayegh CE, Quong MW, Agata Y, Murre C. E-proteins directly regulate expression of activation-induced deaminase in mature B cells. Nat Immunol. 2003;4(6):586-93.

67. Gonda H, Sugai M, Nambu Y, Katakai T, Agata Y, Mori KJ, Yokota Y, Shimizu A. The balance between Pax 5 and Id2 activities is the key to AID gene expression. J Exp Med. 2003;198(9):1427-37.

68. Hauser J, Grundstrom C, Kumar R, Grundstrom T. Regulated localization of an AID complex with E2A, PAX5 and IRF4 at the Igh locus. Mol Immunol. 2016:80:78-90.

69. Nipper AJ, Smithey MJ, Shah RC, Canaday DH, Landay AL. Diminished antibody response to influenza vaccination is characterized by expansion of an age-associated B-cell population with low PAX5. Clin Immunol. 2018;193: $80-7$ 
70. Frasca D, Diaz A, Romero M, Thaller S, Blomberg BB. Metabolic requirements of human pro-inflammatory B cells in aging and obesity. PLoS One. 2019; 14(7):e0219545.

71. Frasca D, Diaz A, Romero M, Blomberg BB. The generation of memory B cells is maintained, but the antibody response is not, in the elderly after repeated influenza immunizations. Vaccine. 2016;34(25):2834-40.

72. Khurana S, Frasca D, Blomberg B, Golding H. AID activity in B cells strongly correlates with polyclonal antibody affinity maturation in-vivo following pandemic 2009-H1N1 vaccination in humans. PLoS Pathog. 2012;8(9):e1002920.

73. Sasaki S, Sullivan M, Narvaez CF, Holmes TH, Furman D, Zheng NY, Nishtala M, Wrammert J, Smith K, James JA, et al. Limited efficacy of inactivated influenza vaccine in elderly individuals is associated with decreased production of vaccine-specific antibodies. J Clin Invest. 2011;121(8):3109-19.

74. Goenka R, Scholz JL, Naradikian MS, Cancro MP. Memory B cells form in aged mice despite impaired affinity maturation and germinal center kinetics. Exp Gerontol. 2014;54:109-15.

75. Jiang N, He J, Weinstein JA, Penland L, Sasaki S, He XS, Dekker CL, Zheng NY, Huang M, Sullivan $M$, et al. Lineage structure of the human antibody repertoire in response to influenza vaccination. Sci Transl Med. 2013;5(171): 171ra119.

76. Dunn-Walters DK, Ademokun AA. B cell repertoire and ageing. Curr Opin Immunol. 2010;22(4):514-20.

77. Martin V, Bryan Wu YC, Kipling D, Dunn-Walters D. Ageing of the B-cell repertoire. Philos Trans R Soc B. 2015;370(1676):20140237.

78. Ju CH, Blum LK, Kongpachith S, Lingampalli N, Mao R, Brodin P, Dekker CL, Davis MM, Robinson WH. Plasmablast antibody repertoires in elderly influenza vaccine responders exhibit restricted diversity but increased breadth of binding across influenza strains. Clin Immunol. 2018;193:70-9.

79. Wang C, Liu Y, Xu LT, Jackson KJ, Roskin KM, Pham TD, Laserson J, Marshall EL, Seo K, Lee JY, et al. Effects of aging, cytomegalovirus infection, and EBV infection on human B cell repertoires. J Immunol. 2014;192(2):603-11.

80. Henry C, Zheng NY, Huang M, Cabanov A, Rojas KT, Kaur K, Andrews SF, Palm AE, Chen YQ, Li Y, et al. Influenza virus vaccination elicits poorly adapted B cell responses in elderly individuals. Cell Host Microbe. 2019; 25(3):357-66 e356

81. Gensous N, Franceschi C, Blomberg BB, Pirazzini C, Ravaioli F, Gentilini D, Di Blasio AM, Garagnani P, Frasca D, Bacalini MG. Responders and nonresponders to influenza vaccination: a DNA methylation approach on blood cells. Exp Gerontol. 2018;105:94-100.

82. Colonna-Romano G, Bulati M, Aquino A, Scialabba G, Candore G, Lio D, Motta M, Malaguarnera M, Caruso C. B cells in the aged: CD27, CD5, and CD40 expression. Mech Ageing Dev. 2003;124(4):389-93.

83. Fang D, Cui K, Hu G, Gurram RK, Zhong C, Oler AJ, Yagi R, Zhao M, Sharma S, Liu P, et al. Bcl11b, a novel GATA3-interacting protein, suppresses Th1 while limiting Th2 cell differentiation. J Exp Med. 2018;215(5):1449-62.

84. Landro L, Damas JK, Halvorsen B, Fevang B, Ueland T, Otterdal K, Heggelund L, Froland SS, Aukrust P. CXCL16 in HIV infection - a link between inflammation and viral replication. Eur J Clin Investig. 2009;39(11):1017-24

85. Saleiro D, Kosciuczuk EM, Platanias LC. Beyond autophagy: new roles for ULK1 in immune signaling and interferon responses. Cytokine Growth Factor Rev. 2016;29:17-22.

86. Zimmermann MT, Oberg AL, Grill DE, Ovsyannikova IG, Haralambieva IH, Kennedy RB, Poland GA. System-wide associations between DNAmethylation, gene expression, and Humoral immune response to influenza vaccination. PLoS One. 2016;11(3):e0152034

87. Frasca D, Diaz A, Romero M, Blomberg BB. Human peripheral late/exhausted memory $B$ cells express a senescent-associated secretory phenotype and preferentially utilize metabolic signaling pathways. Exp Gerontol. 2017;87(Pt A):113-20.

88. Frasca D, Diaz A, Romero M, D'Eramo F, Blomberg BB. Aging effects on Tbet expression in human B cell subsets. Cell Immunol. 2017;321:68-73.

89. Claes N, Fraussen J, Vanheusden M, Hellings N, Stinissen P, Van Wijmeersch B, Hupperts R, Somers V. Age-associated B cells with Proinflammatory characteristics are expanded in a proportion of multiple sclerosis patients. J Immunol. 2016;197(12):4576-83.

90. Colonna-Romano G, Bulati M, Aquino A, Pellicano M, Vitello S, Lio D, Candore G, Caruso C. A double-negative (IgD-CD27-) B cell population is increased in the peripheral blood of elderly people. Mech Ageing Dev. 2009;130(10):681-90.

91. Adlowitz DG, Barnard J, Biear JN, Cistrone C, Owen T, Wang W, Palanichamy A, Ezealah E, Campbell D, Wei C, et al. Expansion of activated peripheral blood memory B cells in rheumatoid arthritis, impact of B cell depletion therapy, and biomarkers of response. PLoS One. 2015;10(6):e0128269.

92. Wehr C, Eibel H, Masilamani M, IIlges H, Schlesier M, Peter HH, Warnatz K. A new CD21low B cell population in the peripheral blood of patients with SLE. Clin Immunol. 2004;113(2):161-71.

93. Chang LY, Li Y, Kaplan DE. Hepatitis C viraemia reversibly maintains subset of antigen-specific T-bet+ tissue-like memory B cells. J Viral Hepat. 2016.

94. Illingworth J, Butler NS, Roetynck S, Mwacharo J, Pierce SK, Bejon P, Crompton PD, Marsh K, Ndungu FM. Chronic exposure to plasmodium falciparum is associated with phenotypic evidence of $B$ and $T$ cell exhaustion. J Immunol. 2013;190(3):1038-47.

95. Moir S, Ho J, Malaspina A, Wang W, DiPoto AC, O'Shea MA, Roby G, Kottilil $\mathrm{S}$, Arthos J, Proschan MA, et al. Evidence for HIV-associated B cell exhaustion in a dysfunctional memory B cell compartment in HIV-infected viremic individuals. J Exp Med. 2008;205(8):1797-805.

96. Hao Y, O'Neill P, Naradikian MS, Scholz JL, Cancro MP. A B-cell subset uniquely responsive to innate stimuli accumulates in aged mice. Blood. 2011;118(5):1294-304.

97. Rubtsov AV, Rubtsova K, Fischer A, Meehan RT, Gillis JZ, Kappler JW, Marrack P. Toll-like receptor 7 (TLR7)-driven accumulation of a novel CD11C(+) B-cell population is important for the development of autoimmunity. Blood. 2011; 118(5):1305-15.

98. Naradikian MS, Myles A, Beiting DP, Roberts KJ, Dawson L, Herati RS, Bengsch B, Linderman SL, Stelekati E, Spolski R, et al. Cutting edge: IL-4, IL21, and IFN-gamma interact to govern T-bet and CD11C expression in TLRactivated B cells. J Immunol. 2016;197(4):1023-8.

99. Russell Knode LM, Naradikian MS, Myles A, Scholz JL, Hao Y, Liu D, Ford ML, Tobias JW, Cancro MP, Gearhart PJ. Age-associated B cells express a diverse repertoire of $\mathrm{VH}$ and Vkappa genes with somatic Hypermutation. J Immunol. 2017;198(5):1921-7.

100. Johnson JL, Rosenthal RL, Knox JJ, Myles A, Naradikian MS, Madej J, Kostiv M, Rosenfeld AM, Meng W, Christensen SR, et al. The transcription factor T-bet resolves memory B cell subsets with distinct tissue distributions and antibody specificities in mice and humans. Immunity. 2020;52(5):842-55 e846.

101. Swain SL, Kugler-Umana O, Kuang Y, Zhang W. The properties of the unique age-associated $B$ cell subset reveal a shift in strategy of immune response with age. Cell Immunol. 2017:321:52-60.

102. Tchkonia T, Morbeck DE, Von Zglinicki T, Van Deursen J, Lustgarten J, Scrable H, Khosla S, Jensen MD, Kirkland JL. Fat tissue, aging, and cellular senescence. Aging Cell. 2010;9(5):667-84.

103. Zamboni M, Rossi AP, Fantin F, Zamboni G, Chirumbolo S, Zoico E, Mazzali G. Adipose tissue, diet and aging. Mech Ageing Dev. 2014;136-137:129-37.

104. Foster MC, Hwang SJ, Porter SA, Massaro JM, Hoffmann U, Fox CS. Fatty kidney, hypertension, and chronic kidney disease: the Framingham heart study. Hypertension. 2011;58(5):784-90.

105. Machann J, Thamer C, Schnoedt B, Stefan N, Stumvoll M, Haring HU, Claussen CD, Fritsche A, Schick F. Age and gender related effects on adipose tissue compartments of subjects with increased risk for type 2 diabetes: a whole body MRI/MRS study. MAGMA. 2005;18(3):128-37.

106. Ryan AS, Nicklas BJ. Age-related changes in fat deposition in mid-thigh muscle in women: relationships with metabolic cardiovascular disease risk factors. Int J Obes Relat Metab Disord. 1999;23(2):126-32.

107. Saisho Y, Butler AE, Meier JJ, Monchamp T, Allen-Auerbach M, Rizza RA, Butler PC. Pancreas volumes in humans from birth to age one hundred taking into account sex, obesity, and presence of type-2 diabetes. Clin Anat. 2007;20(8):933-42

108. Silaghi A, Piercecchi-Marti MD, Grino M, Leonetti G, Alessi MC, Clement K, Dadoun F, Dutour A. Epicardial adipose tissue extent: relationship with age, body fat distribution, and coronaropathy. Obesity (Silver Spring). 2008; 16(11):2424-30

109. Robert L. Aging of the vascular-wall and atherosclerosis. Exp Gerontol. 1999; 34(4):491-501.

110. Najarro K, Nguyen H, Chen G, Xu M, Alcorta S, Yao X, Zukley L, Metter EJ, Truong $T$, Lin $Y$, et al. Telomere length as an Indicator of the robustness of Band T-cell response to influenza in older adults. J Infect Dis. 2015;212(8):1261-9.

111. Blackburn EH. Structure and function of telomeres. Nature. 1991;350(6319): 569-73

\section{Publisher's Note}

Springer Nature remains neutral with regard to jurisdictional claims in published maps and institutional affiliations. 